\title{
O COLÉGIO SANTA ROSA NA DINÂMICA DA "EDUCAÇÃO- PACIFICAÇÃO" DOS "SELVAGENS" DO ARAGUAIA PARAENSE, A PARTIR DA REVISTA CAYAPÓS E CARAJÁS/MEMÓRIA DOMINICANA (1902-1952)
}

\author{
Milton Pereira Lima ${ }^{1}$
}

\begin{abstract}
Resumo: No presente artigo foi realizada uma investigação a respeito do Colégio Santa Rosa, sua fundação e o perfil dos seus estudantes. O surgimento de tal instituição foi articulado por padres dominicanos do Araguaia Paraense, se tornou um marco educacional na fronteira do Araguaia Paraense, que atendia crianças indígenas de variados grupos étnicos e moradores do imenso território de Conceição do Araguaia. Utilizou-se como fonte a narrativa constituinte da revista Cayapós e Carajás/Memória dominicana, além de corpus documentais produzidos pelos missionários entre os anos de 1902 a 1952. O resultado da criação dessa escola foi a articulação de uma educação de perfil elementar para formar cidadãos cristãos. Todavia, se objetivou uma adequação do comportamento dos indígenas ao padrão cultural ocidental, o que ajudou na promoção da "pacificação", na evacuação e na extinção de grupos indígenas araguaianos.
\end{abstract}

Palavras-chave: Indígenas. História da Educação. Memória Dominicana. Fronteira.

\section{COLÉGIO SANTA ROSA IN THE DYNAMICS OF "EDUCATION- \\ PACIFICATION" OF THE "SAVAGES" OF ARAGUAIA PARAENSE IN THE MAGAZINE CAYAPÓS E CARAJÁS/MEMORIA DOMINICANA (1902-1952)}

\begin{abstract}
In the present article, an investigation was carried regarding Colégio Santa Rosa, its foundation, and the profile of its students. The emergence of such an institution was articulated by Dominican priests from Araguaia Paraense, becoming an educational landmark on the border of Araguaia Paraense, that served indigenous children from various ethnic groups, living in the vast territory of Conceição do Araguaia. It was used as a source the constituent narrative of the magazine Cayapós e Carajás/Memória Dominicana, besides a documentary corpus produced by the missionaries between the years of 1902 and 1952. The result of the creation of this school was the articulation of an elementary education profile to form Christian citizens. However, the objective was to adapt the behavior of the indigenous people to the Western cultural standard, which helped to promote "pacification", the evacuation, and the extinction of Araguaian indigenous groups.
\end{abstract}

Keywords: Indigenous people. History of Education. Dominican memory. Border.

\section{EL COLEGIO SANTA ROSA EN LA DINÁMICA DE LA "EDUCACIÓN- PACIFICACIÓN" DEL "SALVAJE" DE ARAGUAIA PARAENSE, DE LA REVISTA CAYAPÓS E CARAJÁS / DOMINICANA MEMORIA (1902-1952)}

Resumen: En este artículo se realizó una investigación sobre el Colégio Santa Rosa, su fundación y el perfil de sus estudiantes. El surgimiento de tal institución fue articulado por sacerdotes dominicanos de Araguaia Paraense, convirtiéndose en un hito educativo en la frontera de Araguaia Paraense, que atendía a niños indígenas de diversas etnias, residentes en el vasto territorio de Conceição do Araguaia. Se utilizó como fuente la narrativa constituyente de la revista Cayapós y Carajás / Memoria dominicana, además del corpus documental elaborado por los

\footnotetext{
${ }^{1}$ Mestre em Dinâmica Territorial e Sociedade na Amazônia - PDTSA - UNIFESSPA (2019). Graduado em Licenciatura em História pela Universidade Estadual Vale do Acaraú (2008). Graduado e licenciatura plena em pedagogia pela Universidade do Estado do Pará (UEPA) (2000). Atua como professor: SEDUC/ PA e SEMEC/Redenção, FIC/PA. É filiado ao Grupo de Pesquisa Territórios Indígenas e Etno-envolvimento.
} 
misioneros entre los años 1902 a 1952. El resultado de la creación de esta escuela fue la articulación de una educación de perfil elemental. formar ciudadanos cristianos. Sin embargo, el objetivo era adecuar el comportamiento de los indígenas al estándar cultural occidental, lo que ayudó a promover la "pacificación", la evacuación y la extinción de los grupos indígenas araguaianos.

Palabras clave: Indígenas. História da Educação. Memória Dominicana. Fronteira.

\section{Introdução}

Em Conceição do Araguaia, às margens do Rio Araguaia, local definido como "Sul do Pará" (PEREIRA, 2015) ou Araguaia Paraense, ocorreram as primeiras práticas educacionais e relações sociais envolvendo indígenas e não indígenas, em um território à época conhecido por "sertão bruto" (GALLAIS, 1903). Este território vinha sendo habitado por colonos, povos nativos e os missionários dominicanos ${ }^{2}$, que se instalaram na região no ano de 1897, após a fundação da Catequese que dá o nome à cidade.

Este artigo tem o propósito de apresentar um momento da história da região citada, que ainda permanece às sombras da investigação historiográfica. Assim, encontra-se justificativa ao se buscar compreender como a proposta pioneira de educação do Colégio Santa Rosa, e seus processos de realização, pode contribuir com a memória de escolarização dessa parte da Amazônia. Não obstante, o recorte pertence a um passado não muito distante, mas que está descoberto pela historiografia, campo do conhecimento que constrói as narrativas históricas da população, a constituição do povoamento e a fundação da cidade de Conceição do Araguaia, bem como sua influência regional.

Além da compreensão do processo educacional inicial dessa região, a relevância da presente pesquisa está em colaborar tanto para o âmbito acadêmico, como ainda para a ampliação do acervo de pesquisas historiográficas acerca dos processos de ofertas educacionais, seus sujeitos e suas relações com a história do presente. Conhecer o passado e o presente possibilita que sejam traçadas perspectivas de futuro. Ainda, outra razão para tal estudo se sustenta no fato de que ele está qualificando o proponente para a realização de pesquisa científica em educação, contribuindo para a ampliação do quadro de pesquisador no Araguaia Paraense e na Região Norte.

São cada vez mais recorrentes e relevantes trabalhos de dissertações e teses que têm se dedicado às investigações de questões educacionais da região Amazônica em

\footnotetext{
${ }^{2}$ Ordem religiosa católica fundada por São Domingos de Gusmão em 1216 em Tolouse no sul da França. Recebeu oficialmente o nome de Ordem dos Pregadores. O cerne do carisma dominicano se pauta nos estudos e no ensino. 'Contemplar e transmitir o fruto da contemplação' - um pensamento de Santo Tomás de Aquino (1225-1274), membro da Ordem, grande filósofo da escolástica - sintetiza, entre outros, o pressuposto da filosofia dominicana. (BRESSANIN, 2018, p. 3).
} 
contextos históricos. Por exemplo, o estudo de Bressanin (2020), com enfoque na "Educação e Missão em Espaços da Amazônia", trata da trajetória, presença e atuação da missão dominicana e sua prática educacional entre os estados do Tocantins e do Pará nas primeiras décadas do século passado.

Ressalta-se que no espaço e período em que se deu o encontro entre religiosos, colonos e indígenas, também se iniciou um processo de educação que foi além da catequização. Com base na documentação "memória dominicana" e na "revista Cayapós e Carajás" é possível fazer uma aproximação com as leituras dessas fontes sobre a formação do Colégio Santa Rosa, a mais antiga escola da região, criada pelos missionários dominicanos, no ano de 1902, para educar tanto crianças indígenas, como não indígenas do povoado de Conceição do Araguaia. Essa escola desenvolveu suas atividades até o ano de 1952, conforme explicam Bressanin e Almeida (2020), que estudaram a atuação da Missão dominicana no processo de escolarização em quatro cidades da Amazônia no início até meados do século XX.

Nestas cidades, a Congregação das Irmãs Dominicanas de Nossa Senhora do Rosário de Monteils instituiu colégios no período de 1902 a 1952. A educação dominicana-anastasiana, nesta região da Amazônia, foi responsável por lançar luzes sobre as desafiadoras realidades em que se inseriu, inspirou a formação de inúmeras gerações e marcou época (BRESSANIN; ALMEIDA, 2020, p. 67).

Dentre esses colégios instituídos pela Congregação Dominicana, se encontra o Colégio Santa Rosa de Conceição do Araguaia, responsável pelo pioneirismo educacional da Região do Araguaia Paraense e pela escolarização de pelo menos cinco gerações, tornando-se um marco na história da cidade e da população local.

Sobre a existência dessa instituição escolar - mesmo na memória das gerações mais jovens - é muito presente o significado que o Colégio Santa Rosa tem para a história da cidade e da educação das gerações pretéritas. Trata-se de um indicativo de que os egressos conseguiram, por meio da oralidade, transmitir e guardar informações gerais acerca da escola onde iniciaram e, às vezes, até concluíram sua escolarização, conforme era exigido no início do século passado na legislação brasileira.

Informações genéricas dão conta da importância da "presença e a atuação da missão dominicana, a partir de suas instituições escolares, nos espaços da Amazônia, nos estados do Tocantins e do Pará" (BRESSANIN; ALMEIDA, 2020, p. 67). No entanto, até o presente momento pouco se conhece sobre a proposta de educação desenvolvida nessa instituição e os elementos que fizeram parte de sua constituição nesse local. 
DOI: 10.47694/issn.2674-7758.v3.i7.2021.4763

Diante da existência dessa escola, que teve abrangência e influência de escolarização sobre a população de toda uma região, algumas questões ainda estão sem respostas, assim, inqueriu-se as fontes quanto a: Como se configurava a educação missionária dominicana no Colégio Santa Rosa, durante o processo de escolarização dos agrupamentos indígenas e não indígenas no Araguaia paraense, no período de 1902 a $1952 ?$

Objetivou-se conhecer quais eram os atores sociais envolvidos nas práticas de ensino e aprendizagem no espaço pedagógico do colégio. Qual matriz de pensamento orientava as relações de ensino e aprendizado no colégio e quais eram as expectativas educacionais em relação ao público que o frequentava em Conceição do Araguaia?

Conforme Souza (2017), Conceição do Araguaia foi fundada em 1897 pelo dominicano francês Frei Gil de Vila Nova, a partir da missão católica que tinha como objetivo catequizar os índios, que em sua maioria eram os Karajá e Kayapó (IANNI, 1978. Segundo Cruz (2014). Somente após a autorização de seus superiores dominicanos da Europa, concedendo a liberdade de escolher um ponto na margem direita do rio Araguaia para a catequização da população nativa existente na região, foi que Frei Gil de Vila Nova instalou o aldeamento religioso denominado de Conceição do Araguaia. O nome foi uma homenagem do fundador a Nossa Senhora da Conceição e ao rio Araguaia que o acompanhou durante praticamente toda a viagem no interior da Amazônia (CRUZ, 2014, p. 12).

A imposição religiosa de cristãos católicos aos indígenas marcou a fundação do município, "Conceição do Araguaia. O povoado e o município, nasceram do encontro, comunhão e antagonismo entre cristãos e índios, sob a direção de religiosos dominicanos e a propósito de bens espirituais e materiais" (IANNI, 1978, p. 9). Essa relação se dava numa área que até hoje é considerada território religioso da Diocese de Conceição do Araguaia e que, na literatura, vem sendo nomeada por alguns autores de Região do Araguaia paraense. O mapa a seguir mostra a abrangência do espaço citado. 
DOI: 10.47694/issn.2674-7758.v3.i7.2021.4763

Figura 1: Mapa da Prelazia de Conceição do Araguaia

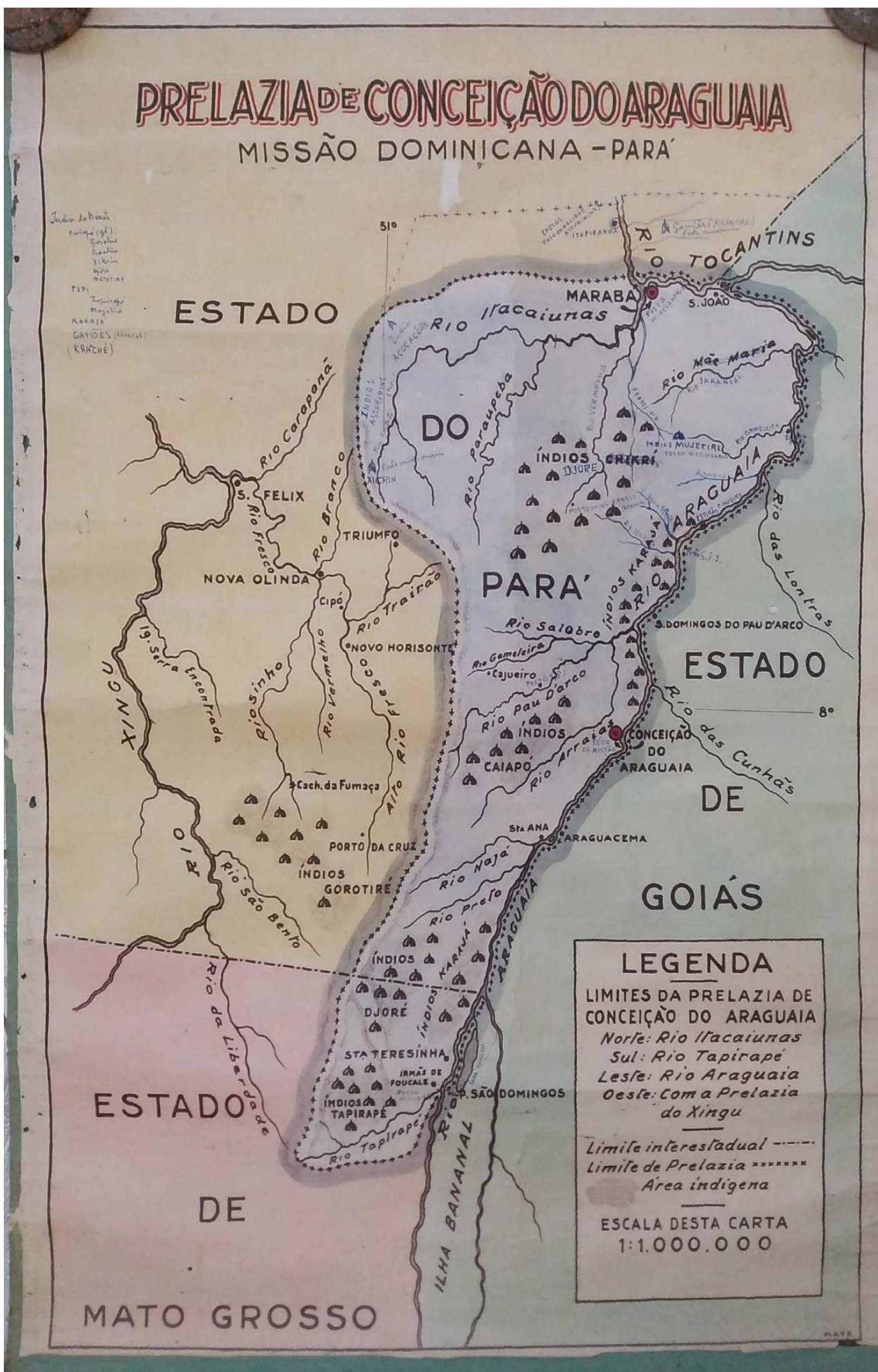

Fonte: Arquivo Bartolomeu de Las Casas, 2017. 


\section{As fontes e o referencial teórico-metodológico}

A presente investigação foi operacionalizada tendo como tipos de fontes de estudo a materialidade discursiva documental, exclusivamente dominicana; ela nos permitiu esclarecer suas concepções, suas maneiras de entender a realidade brasileira e, dentro dela, articular seu projeto de educação no Colégio Santa Rosa, em Conceição do Araguaia. Assim, foi possível compreender como o projeto educacional missionário se configura e se materializa na realidade amazônica.

As primeiras fontes - primárias - são compostas por textos impressos que compõem a documentação de origem na Ordem dos Dominicanos. São livros e periódicos (memórias, biografias, ensaios, relatos de viagens), além de livros de escritores missionários. Ainda, lança-se mão da "revista Cayapós e Carajás", um periódico produzido pelos padres dominicanos entre os anos de 1922-1933.

Na sequência encontra-se um resumo das fontes citadas:

A "COLEÇÃO: MEMÓRIA DOMINICANA" consta de publicações periódicas de responsabilidade da Ordem dos Padres Pregadores sediados no Brasil. Mais especificamente, era uma criação das Dioceses de Uberaba, Belo Horizonte, Conceição do Araguaia, enfim, dos missionários e membros da Igreja Católica em suas campanhas de divulgação das ações religiosas, biografias e vida comunitária das missões. Ao longo de décadas os padres e seus apoiadores publicaram uma variedade de textos sobre inúmeros assuntos. Muitos deles fornecem um material de pesquisa valioso para futuras pesquisas no campo das ciências humanas. Abaixo veja os 10 primeiros números publicados de um total de mais de 170. A sequência é a seguinte 1- Frei Gil Vilanova, 2- Frei Vicente de Melo, 3- Frei Guilherme Vignau, 4 - Frei Estevão Gallais, 5- Frei Ângelo Dargaignaratz, 6- Frei Raimundo Anfossi, 7- Frades Dominicanos no Brasil, 8Frei Gil Vilanova e suas excursões em busca dos índios, 9 - Frei Antônio Sala, 10- Radio Educadora do Araguaia. (MEMORIA DOMINICANA, 2017).

Continuando a descrição das fontes, vide:

A Revista Cayapós e Carajás, é uma das fontes principais desta proposta de investigação, ela foi um periódico produzido pelos padres dominicanos e circulava em nome de Prelazia de Conceição do Araguaia, entre os anos de 1922 e 1933. Nessa revista, temos notícias especialmente da ação evangelizadora da Ordem dos Pregadores (O.P.) no Araguaia. A revista tinha periodicidade de quatro edições ao ano, nos meses de julho, outubro, janeiro e abril. Era vendida e distribuída entre fiéis católicos, principalmente aqueles das regiões sudeste, centro-oeste e sul do País. O acervo físico da revista encontra-se no Arquivo Bartolomeu de Las Casas, em Belo Horizonte, Minas Gerais. Nesse arquivo, encontra-se uma vasta coleção de textos, mapas, relatórios, atas de fundação de cidades, vilas, escolas, hospitais, conventos e igrejas. (LIMA, 2019). 
DOI: 10.47694/issn.2674-7758.v3.i7.2021.4763

A narrativa missionária foi escolhida como corpus para análise porque contextualiza a reprodução discursiva de memorialistas, pesquisadores e historiadores. Esses discursos versam sobre a formação territorial às margens do Araguaia, auxiliando na descrição sobre a colonização da Amazônia brasileira. Especialmente aqui, enfocamos a formação da educação na cidade de Conceição do Araguaia.

Essa narrativa foi elaborada concomitante à prática missionária, portanto, trata-se de uma prática discursiva e social ao mesmo tempo. Os padres "intelectuais dominicanos", ao passo que evangelizavam e educavam, também escreviam sobre suas próprias ações. Dessa forma, se comunicavam com os seus superiores no Brasil e na França a partir de cartas, relatórios e livros de registro. Além disso, por meio dos seus inúmeros periódicos, mantinham os fiéis de outras regiões do Brasil informados quanto à realização da missão em Conceição do Araguaia, ao mesmo tempo em que conseguiam arrecadar fundos para a missão por meio da venda desse material. Exemplo disso são a revista Cayapós e Carajás, o jornal O Araguaia, o jornal O Santo Rosário, dentre outros.

Durante a sistematização das fontes, realizou-se a qualificação e a tematização dos enunciados, optando-se por assuntos recorrentes em ambas as fontes. Esse momento da investigação foi a chave para a construção do artigo, uma vez que se tratou da tentativa de construção de possíveis composições de temáticas que se vinculassem aos objetivos da pesquisa, conferindo sentidos e significados aos dados contidos nos documentos.

É importante ressaltar que ao se trabalhar com um corpus material que denuncia as ações humanas, no universo de pesquisa, a ética ao aspecto humano deve prevalecer. Cabe lembrar que refletir sobre a educação na Região do Araguaia paraense é adentrar também nos processos de escolarização da Amazônia, enfim, aprofundar-se na história, o que implica reconhecer a complexidade que se expressa em sua vasta territorialidade. Conforme Colares (2011), a Amazônia se trata de um conceito construído, arbitrário, carregado de intencionalidades e de historicidade. O espaço geográfico amazônico passou e continua passando por diversas alterações, sendo que as mais significativas correspondem aos contextos de investida na busca de riquezas.

A fauna e a flora, assim como a composição química do solo, do subsolo, das águas e do ar, também se alterou e continua sendo alterada, e os estudos nesses campos mostram-nos que não há uma Amazônia “cristalizada". O espaço amazônico está em construção. Da mesma forma, a composição humana amazônica é dinâmica, múltipla e, em vários aspectos, singular, sendo ainda pouco conhecida, especialmente se for considerada a amplitude do território e as grandes irregularidades na presença humana.

Revista Escritas do Tempo - v. 3, n. 7, jan-abr/2021 - p. 47-63 
Considera-se a importância dos estudos e das pesquisas centrados em objetos que estão mais próximos da nossa realidade, até para que possamos com maior precisão entender e agir sobre ela. No entanto, entende-se que a educação (notadamente a educação escolar) extrapola a localidade geográfica em que ela é realizada. O local não pode prescindir do regional, do nacional, e até mesmo do internacional. Em outros termos, há necessidade permanente de articular o singular e o universal para o melhor entendimento de nosso objeto de estudo. Isso significa que, ao se falar de Conceição do Araguaia ou Araguaia paraense, invoca-se um lugar amazônico, que abriga suas especificidades, dentre elas, a memória do processo educacional da população local.

Produzir história da educação em Conceição do Araguaia, como em qualquer outra região da Amazônia e do Brasil, conforme Colares (2019), exige uma atitude de diálogo com o já existente e de articulação com os que se dispõem a compreender a região, em seus múltiplos aspectos. Isso implica dizer também que se trata de um empreendimento coletivo. Então, lançar mão de resultados de outros estudos, nos mais diversos campos do conhecimento, e que lançam luzes para a compreensão do fenômeno educacional, é tarefa quase impossível para um pesquisador isolado, por mais estudioso, organizado, dedicado e competente que seja.

Em busca desse diálogo com parte da literatura já produzida sobre a história da educação e as especificidades dessa relação, considera-se esclarecedora a opinião de Almeida (2018):

[...] se história da educação pretender ser história e promover estudos que levem em consideração sua natureza histórica, ela deve não somente dispor de fontes, mas também sugerir temas, provocar interrogações e desnaturalizar o que foi tido como dado do passado. Com esses devidos cuidados, a história da educação tem amplas possibilidades de cunhar seu próprio espaço nos estudos em história, desde que não abra mão de fazer a crítica ao que foi produzido em educação e fazer de tudo para romper as fronteiras entre a história e a história da educação (ALMEIDA, 2018, p. 11).

Nota-se que há interesse pelos campos da historiografia e da educação em aproximar o diálogo acerca das possibilidades que a primeira possui de contribuir com o debate educacional, e desvelar conhecimentos que são propícios da história, mas que também se tornam objeto das reflexões da educação, por serem objetos de ensino e aprendizagem. 


\section{O Colégio santa Rosa e seus estudantes}

Na primeira edição da revista Cayapós e Carajás (doravante identificada pela sigla RCC), datada de julho de 1922, o periódico traz informação da chegada das irmãs: “[...] os missionários com o auxílio das Religiosas Dominicanas de Monteils, chegadas em dezembro de 1902 se empregavam na catequese dos índios Cayapós, aldeados perto de Conceição" (RCC, n 1, Ano 1922, p. 2). As freiras foram convidadas por Frei Gil Vilanova, fundador de Conceição, para atuarem como professoras dos "selvagens" no povoado, naquilo que se pode considerar um misto de escola e catequese:

A priorização da "educação das crianças longe dos ambientes nativos, a polícia constante da conduta civil dos índios, fixação, sujeição e educação", são as mesmas estratégias de catequização de outras missões, que foram repetidas na fronteira do atual Sul do Pará, nos arraiais às margens dos rios, em vilarejos, e em agrupamentos indígenas distantes. Após a aglutinação dos indígenas num dado local, conforme Pic (2014) passava-se ao processo de "educação" que era a "ponta de lança" cultural dessa ação religiosa, e por esse processo "educativo", moral, inculcava-se os costumes/tradições não-indígenas que deveriam ser incorporados pelos agrupamentos indígenas. (LIMA, 2019, p. 40)

Educar as crianças indígenas no Colégio Santa Rosa, ou seja, distante da aldeia e dos pais das crianças, além de toda a estrutura que se podia lançar mão nas práticas pedagógicas e sacramentais, também dificulta a fuga dos estudantes para as matas próximas da escola. A seguir, fotografia da referida instituição de ensino dominicana em dois tempos:

Figura 2: Fotografia antiga do Colégio Santa Rosa



Fonte: Gallais, 1954. 
Figura 3: Fotografia do Colégio Santa Rosa na atualidade

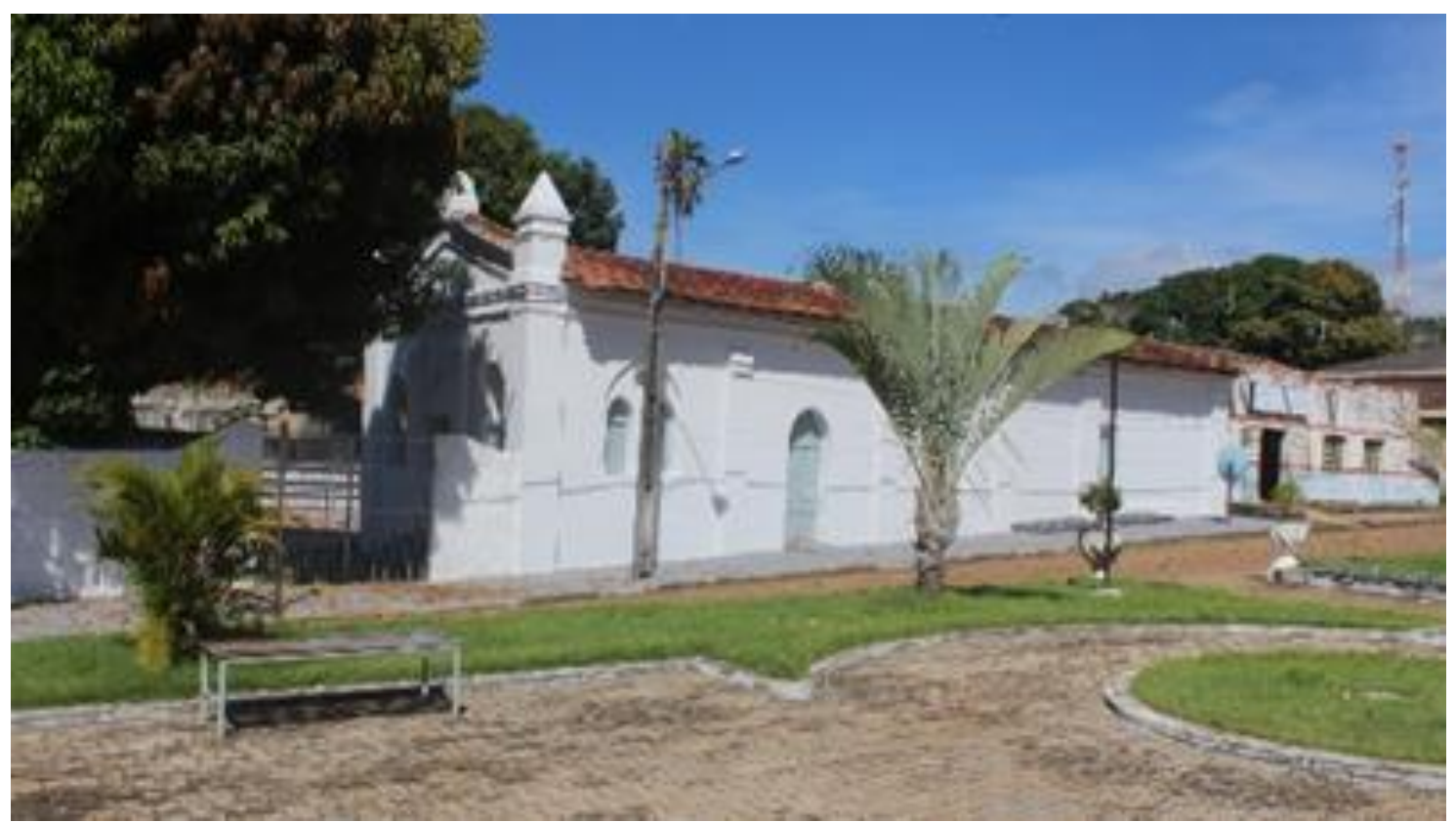

Fonte: Lima, 2019.

A aldeia dos Kayapó se localizava à quatro léguas do povoado (aproximadamente $20 \mathrm{Km}$ ) (GALLAIS, 1954), era dessa aldeia - e de várias outras tanto do lado paraense, como do Norte do Goiás - que as crianças indígenas eram trazidas para serem educadas no Colégio Santa Rosa e posteriormente catequizadas e batizadas. A seguir, é narrada a chegada de estudantes indígenas à Catequese/escola para serem preparados para o batismo:

Chegou em Conceição um grupo de Índios Cayapós, pertencentes à pequena aldeia de Croatá. Eram nove homens, cinco mulheres e seis crianças. Foram logo ter com o Snr. D. Frei Sebastião. Vinham cumprir o prometido e entregar-lhe cinco meninos para catequizá-los. São estes: $1^{\circ}$ - Rufino Oka, 12 anos, que já teve aqui um princípio de catequese, faz quatro anos; é ainda pagão. $2^{\circ}$ - Angelo Kudjuré, 10 anos, batizado na aldeia por Frei Francisco. $3^{\circ}$ - Cicero Kongrâ, 7 a 8 anos, batizado por Frei José e afilhado de dona Archaja. $4^{\circ}$ - Bendjainá, 7 anos, ainda pagão. $5^{\circ}$ - Bedjié, 5 anos, o Benjamim da turma, também pagão. São todos órfãos de pai e mãe, menos Bendjainá que ainda tem a mãe. Foram confiados aos cuidados da veneranda e carinhosa viúva e Terceira Dominicana D. Archaja, chamada "Mãe dos Cayapós". É uma das dedicadas matronas que muito auxiliaram o finado Frei Gil e os seus companheiros e sucessores na obra da Catequese. Todas as despesas da educação desses pequenos indígenas correm por conta do Snr. Prelado. Esperam-se outros, meninos e meninas, daqui a pouco. As crianças do sexo feminino serão entregues às mui dedicadas Irmãs Dominicanas, exímias catequistas e mestras. Brevemente os cinco Cayapósinhos iniciarão o estudo do BA BA sob a direção das referidas religiosas. (RCC, $\mathrm{n}^{\circ}$ 1, Ano 1922, p. 5. Grifo nosso) 
Apesar de os missionários reclamarem da ausência do estado naquilo que seria de sua competência e responsabilidade, ou seja, criar e manter unidades de ensino, os padres articulavam a abertura de novas escolas sertão adentro, mesmo tendo de enfrentar "gastos anuais com as escolas, despesas com materiais de escola, de funcionamento, de roupas


continuavam sua saga "no Pará, foi criado uma escola em Santa Therezinha, no Sul da Prelazia e do Estado paraense; outra em São Pedro da Gamelleira, situado pelo lado poente, na entrada da Mata Geral do Thiunpho; na beira de Santa Anna" (RCC, n 32, Ano 1930, p. 4. Grifo nosso).

A Prelazia de Conceição do Araguaia, apoiada pelos seus "benfeitores" - que eram pessoas de outras partes do Brasil que financiavam a catequese - anunciou em 1903 a fundação de mais uma escola "quarto colégio: Estrela da manhã. Augura-se bom êxito desta empresa por ser a tribo Tapirapé de índole pacífica, de inteligência mais prompta e de desenvolvimento mais adiantado". (RCC, nº 7, Ano 1924, p. 9 Grifo adicionado).

Ao ir ao encontro da história da educação dominicana, ocorrida no início do século XX em Conceição do Araguaia, entende-se, até aqui, que essa educação, conforme define Bressanin (2018), trabalha a análise de conceitos a partir de contextos sociais ou políticos e suas ressignificações na evolução histórica, propondo historiar o conceito de Educação Dominicana no Brasil. Assim:

Para a Ordem Dominicana aprender e ensinar estão na base de seu carisma e de sua organização. Domingos de Gusmão não deixou nada escrito e nem elaborou pressupostos de uma Educação Dominicana, mas somente lançou as bases de sua fundação embasada num serviço em prol da verdade que liberta, na prática da simplicidade que rompe com toda e qualquer forma de luxo e riqueza, na compaixão e na misericórdia para com o outro, no poder em forma de serviço, no estudo sério, dedicado e profundo e na pregação (ensino) virtuosa que proporciona transformações. (BRESSANIN, 2018, p. 9).

Ao buscar investigar sobre a Educação Dominicana em um contexto bem distante geográfico e temporal da sua origem, buscou-se compreender como essa educação se configurou em Conceição do Araguaia, um "povoado" que nascia às margens do Rio Araguaia, na entrada da Região amazônica, nos primeiros cinquenta anos do século XX. Dessa maneira, procurando perceber as permanências e as alterações da proposta original no tempo e no espaço evidenciados, visto que "a precisão metodológica da história dos conceitos foi uma decorrência direta da possibilidade de se tratar conjuntamente espaço e tempo, com a perspectiva sincrônica de análise" (KOSELLECK, 2006, p. 104 apud BRESSANIN, 2018, p. 3). 
DOI: 10.47694/issn.2674-7758.v3.i7.2021.4763

O padre e escritor da Ordem dos Pregadores, Gallais (1903), explica que a fundação do Colégio Santa Rosa atendia aos seguintes ideais:

O plano dos missionários seria, pois, de subtrair bem cedo as crianças de ambos os sexos da influência do meio em que nasceram, de impedi-las de contraírem os hábitos da vida selvagem e de lhes incutir ao contrário, os da vida cristã, de lhes dar com a instrução religiosa, o ensino elementar que se dar nas escolas primárias (GALLAIS, 1903, p. 50).

Em seguida, os próximos passos que esses estudantes deveriam dar, após estarem "formados" nas primeiras letras, seria o batizado, o casamento, e formar família, abandonando completamente seu estilo e hábitos de vida "selvagem". Contudo, para o antropólogo Moreira Neto "o processo de povoação que, com rapidez e intensidade dramática, incidiu sobre a sub-tribo Kayapó de Pau D'arco, terminando por extingui-la totalmente" (1960, p. 77). Portanto, a tentativa de incorporar aos indígenas, modos de vida semelhantes aos dos não indígenas, culminou com a "pacificação" dessas etnias, favorecendo mais tarde a implantação de fazendas e empreendimentos agrícolas, que expulsaram e exterminaram os grupos indígenas da região.

Ressalta-se que, conforme Bressanin (2018), para historiar o conceito de Educação Dominicana no Brasil, é preciso voltar aos primórdios dessa concepção que está inserida no contexto do século XIII, no sul da França, a partir das motivações que levaram Domingos de Gusmão a reunir um grupo de pessoas para viver de maneira comunitária alguns elementos do cristianismo primitivo. Toda abordagem sobre Educação Dominicana deve tomar como base, e refletir, o espírito e a visão de São Domingos.

No Brasil, a Ordem Dominicana se instalou em 1881 na cidade de Uberaba, interior de Minas Gerais, e se espalhou por diversos outros estados como Goiás, Pará, São Paulo e Paraná. Em cada convento fundado para o trabalho missionário eclesial, os projetos educativos eram preponderantes:

O historiador eclesiástico Cônego Trindade afirmou que “[...] onde ia o escapulário do padre dominicano, logo em seguida, em se completando, lá vinha o hábito da irmã religiosa dominicana" (SILVA, 2006, p. 420). Riolando Azzi afirmou que a chegada e a instalação dos religiosos dominicanos no Brasil abriram caminhos "para a vinda das Irmãs Dominicanas do SS. Rosário, cuja atividade principal foi a educação da juventude". (BRESSANIN, 2018, p. 12).

A partir dessa chegada, a historiografia registra a distribuição espacial de escolas fundadas por essa ordem, construindo um significativo capítulo da escolarização da 
população brasileira, em especial, a educação feminina. De acordo com o citado autor, seguindo a tradição da congregação, as primeiras instituições educativas dominicanas no Brasil configuraram-se como internatos e externatos para o sexo feminino. Diante da precariedade da educação para meninas no Brasil, no final do século XIX, a Educação Dominicana tornou-se uma expressiva alternativa para as famílias abastadas - das cidades que tiveram os colégios implantados - que projetavam uma formação mais arrojada para suas filhas.

Vale ressaltar que as instituições educacionais dominicanas não eram um espaço educacional destinado às filhas da classe rica, por mais que elas precisassem dos recursos para se manterem funcionando, havia estratégias para garantir espaço em seu corpo discente para meninas das famílias pobres também, como se percebe nesse excerto:

\begin{abstract}
Apesar do internato não ser gratuito encontram-se registros de que "as freiras aceitavam quaisquer bens que fossem úteis no internato, como por exemplo gêneros alimentícios" (OLIVEIRA, 2010, p. 75) o que facilitava para as meninas mais carentes estudarem. Ressalta-se que o primeiro estatuto da Congregação das Dominicanas rezava no artigo $6^{\circ}$ que "o ensino das jovens e principalmente das pobres, será uma das finalidades do Instituto" (MESQUITA, 2010, p. 153). Outra modalidade que propiciava as meninas pobres de matricularem-se nos colégios dominicanos era a das "martinhas" que estudavam num período e no outro dedicavam-se à limpeza do prédio, a ajudar na cozinha ou a lavar roupas. Elas não desfrutavam de todo o currículo oferecido pela educação dominicana de então, mas tinham a oportunidade de estudarem apesar de viverem numa sociedade em que a rígida hierarquia social existente preconizava a escola para os ricos (MELO, 2002; DOURADO 2010; CAMARGO, 2014).
\end{abstract}

Ainda apoiado em Bressanin (2018) e suas referências, com esses arranjos inclusivos, a Educação Dominicana formou muitas jovens - até mesmo entre os indígenas em Conceição do Araguaia - visto que o Colégio ali fundado foi uma maneira de contribuir com a ‘obra de evangelização’ junto aos índios Kayapó e Karajá, entre outras etnias. Nesse caso, o Colégio Santa Rosa teria sido obra “das irmãs Maria Otávia, Denise, Luiza e Maximina”. Em seu livro Memórias Araguianas entre Becos, Barrocas, Areões e Banzeiros (2018), obra composta por uma rica narrativa oral de velhos moradores da cidade Conceição do Araguaia, o historiador Isau C. Luz narra o seguinte depoimento de um egresso do Colégio Santa Rosa:

O ensino naquela época era o regional, então era até a quarta série. Elas tinham aulas de latim, de música, química, inglês, francês (...) Além das matérias pedagógicas tinha a religião, que era matéria mesmo, tinha economia doméstica, tinha essas boas matérias, aulas de bordado, preparar enxovais, conhecimentos de enfermagem (LUZ, 2018, p. 216-217). 
Aqui é possível inferir que a educação dominicana também atendia às expectativas de um projeto civilizador inserido no espírito ultramarino e reformador da missão católica no Brasil, no contexto do final do século XIX e início do século XX. Educava-se nas primeiras letras, mas com uma mescla de utilitarismo pedagógico com aspectos morais religiosos.

Essa ideia de uma educação civilizatória permeou a prática da educação dominicana no Brasil, não só na perspectiva da educação dos indígenas, mas estava presente no cotidiano de suas escolas, especialmente as fundadas em regiões interioranas e sertanejas, em que a ação educativa das religiosas ultrapassava o currículo básico e diversificado e alcançava a introdução de novos hábitos através de aulas de etiqueta 'à francesa' e inserção de costumes, como os alimentares - de consumir verduras - ou de se vestir e falar (OLIVEIRA, 2010).

Por outro lado, pode se dizer que:

A "pacificação" e a "civilização" são dois termos costumeiramente repetidos nos discursos dos evangelizadores, onde se lê: "será ainda possível a pacificação e civilização desses silvícolas tão bravios e tão fugitivos?" (RCC, $\mathrm{n}^{\circ}$. 07.Ano. 1924. p.7, grifo nosso). Mesmo que os significados dos termos citados tenham relações históricas e culturais, as consequências dessa ação, promovida pela referida ordem, foram: genocídio, pacificação e racismo (LIMA, 2019, p. 33)

O fato de a cidade de Conceição do Araguaia ter a sua gênese como fruto da missão dominicana francesa da província de Toulouse que se instalou no Brasil em 1881 -, o Colégio Santa Rosa e a formação da cidade e da Diocese são parte do processo de territorialização do projeto educacional da ordem dominicana no interior do Brasil incluindo a Amazônia. Assim, torna-se impossível refletir sobre a educação dominicana no Brasil sem mencionar sua presença nessa parte da Amazônia.

\section{Considerações finais}

Nas últimas décadas houve uma expansão de pesquisas sobre educação no Brasil, sendo, então, necessária a realização de estudos historiográficos ou da história da educação e dos processos educativos na Amazônia. Sendo assim, ressalta-se que são cada vez mais recorrentes as investigações que interpretam o passado educacional sob uma polifonia de escrita de pesquisadores de várias regiões do Brasil, que contribuíram para a consolidação da história da educação. 
DOI: 10.47694/issn.2674-7758.v3.i7.2021.4763

Neste artigo, discutiu-se sobre a implantação do Colégio Santa Rosa em Conceição do Araguaia, no ano de 1902, quando os missionários dominicanos criaram escolas para crianças indígenas e filhos de sertanejos ao longo do imenso território de sua diocese, que se estendia até são Felix e as proximidades da cidade Marabá. Esse contexto representa o marco fundador da educação no Araguaia Paraense ou Sul do Pará.

Foi possível debruçar-se sobre uma vasta documentação oriunda da "Memória Dominicana" - e a revista Cayapós e Carajás (1922-1933), documentos que compõem distintos materiais escritos, muitos inéditos, produzidos pela Ordem dos Padres Pregadores da Diocese de Conceição do Araguaia. O recorte aqui explorado tematiza sobre as características e as circunstâncias da educação elementar nos primeiros anos do século XX.

Sendo assim, neste texto evidencia-se dois momentos sobre tais práticas educacionais; um deles diz respeito às primeiras medidas e ações educacionais promovidas pelas freiras ou "matronas" dominicanas dentro do território da catequese de Conceição do Araguaia, ocorrido já após a fundação do Colégio Santa Rosa do ano de 1902 até 1922. O segundo momento segue logo após esse período até o ano de 1952, data essa que demarca a formação das últimas classes no Colégio dos dominicanos no Araguaia.

O resultado da formação de núcleos/escolas articuladas pelos padres da Ordem dos Pregadores do lado paraense do rio Araguaia, tinha à frente os missionários críveis de sua missão de salvação das almas daqueles que eles denominavam "selvagens", habitantes do "deserto de almas". Os padres planejavam uma prática educativa que primava pela aquisição da leitura e da escrita e culminava com a adesão à cultura cristã, via batismo e casamento ao estilo ocidental.

Contudo, a "pacificação" - "conversão" dos grupos étnicos aos costumes dos cidadãos/cristãos corroborou com a dispersão e/ou o extermínio dos povos da floresta, conforme assegura Moreira Neto (1960). As propostas para "educar" ou tornar os indígenas cidadãos fracassaram, e as tentativas de "aproveitamento" destes povos, seguindo projeto de Couto Magalhães, eram enaltecidas pelos dominicanos ( $\mathrm{RCC}, \mathrm{n}^{\mathrm{o}} 10$. Ano. 1924, p. 2-3), cujas pretensões idealizavam o uso da mão de obra dos grupos étnicos pacificados. Esses deveriam fornecer a lenha para as embarcações de empresários que pretendiam comercialmente navegar e escoar seus produtos via os rios Tocantins e Araguaia. 


\section{Referências}

ALMEIDA, Vasni (org.). História da educação e método de aprendizagem em ensino de história. Palmas/TO: EDUFT, 2018.

BRESSANIN, César Evangelista Fernandes; ALMEIDA, Maria Zeneide Carneiro Magalhães. Educação e Missão em espaços da Amazônia: experiências da congregação das irmãs dominicanas de Monteils. Revista Humanidades e Inovação. v. 7, n. 15, 2020.

BRESSANIN, César Evangelista Fernandes. História do Conceito de Educação Dominicana. RCE, v.3, 2018 ISSN 2526-4257 e019006.

CAMARGO, Kenia G. F. Educação católica e presença dominicana em Goiás (GO): a cultura escolar do colégio Sant'Anna (1940-1960). Dissertação (mestrado em Educação) - Universidade Estadual de Mato Grosso do Sul, Unidade Universitária de Paranaíba. Paranaíba, MS: UEMS, 2014.

COLARES, Anselmo Alencar. HISTÓRIA DA EDUCAÇÃO NA AMAZÔNIA. Questões de Natureza Teórico-metodológicas: Críticas e Proposições Revista HISTEDBR On-line, Campinas, n. Especial, p. 187-202, out.2011.

CRUZ, Thiago Silva da. A produção do espaço urbano na Amazônia: A Influência da igreja católica na formação sócio-espacial do município de Conceição do Araguaia - PA. Revista GeoAmazônia, Belém, v. 2, n. 04, p. 122-145, 2014.

GALLAIS, Estevão M. Entre os índios do Araguaya. Tradução: Octaviano Esselin. São Paulo: Escola Tipográfica Salesiana, 1903. 55 p.

GALLAIS, Estevão Maria, O.P. O apóstolo do Araguaia: Frei Gil Vilanova missionário dominicano. Prelazia de Conceição do Araguaia, 1954.

IANNI, Otávio. A Luta pela terra: história social da terra e da luta pela terra numa área da Amazônia. V. 8. Petrópolis: Editora Vozes, 1978.

LIMA, Milton Pereira. O discurso dos missionários dominicanos sobre os indígenas do Araguaia na revista Cayapós e Carajás. 2019. Dissertação (Mestrado em Dinâmica Territorial e Sociedade na Amazônia) _ Universidade Federal do Sul e Sudeste do Pará, Marabá, Pará, 2019. Disponível em: https://pdtsa.unifesspa.edu.br/produ\%C3\%A7\%C3\%A3oacad\%C3\%AAmica/dissertaco es.html. Avesso em: 22 abril.2021.

LUZ, Isaú Coelho. Memórias Araguianas entre Becos, Barrocas, Areões e Banzeiros. Goiânia: Kelps, 2018.

MELO, Geovana F. Por trás dos muros escolares: luzes e sombras na educação feminina. Colégio Nossa Senhora das Dores - Uberaba (1940-1966). Dissertação (Mestrado em Educação) Universidade Federal de Uberlândia. Uberlândia, 2002.

MOREIRA NETO, Carlos A. A Cultura Pastoril do Pau d' Arco. Boletim do Museu Paraense Emílio Goeldi. INPA, CNPq, n. 10, março, 1960. 
OLIVEIRA, Maria de F. Entre o sertão e o litoral: cultura e cotidiano em Porto Nacional 1880/1910. Anápolis: Universidade Estadual de Goiás, 2010.

PEREIRA, Airton dos Reis. Do posseiro ao sem-terra: A luta pela terra no Sul e Sudeste do Pará. Editora UFPE, Recife, 2015

PRELAZIA DE CONCEIÇÃO DO ARAGUAIA. [Relatório] 1896-1933 Missão Dominicana. Arquivo da província Dominicana Frei Bartolomeu de Las Casas, Seção Histórica, [S.D.].

PRELAZIA DE CONCEIÇÃO DO ARAGUAIA. [Revista Caiapó e Carajá] 1922-1933. Arquivo da província Dominicana Frei Bartolomeu de Las Casas, Seção Histórica, [S.D.].

SOUZA, Dayane Olivério de. Saberes matemáticos empíricos de pescadores da colônia Z-39 de Conceição do Araguaia - PA. Dissertação de Mestrado. Universidade Federal Rural do Rio de Janeiro. Seropédica, RJ, 2017.

Artigo recebido em 30 de janeiro de 2021. Aprovado em 30 de abril de 2021. 